\title{
Intestinal Perforation by Saline Total Gut Lavage in Occult Diverticulitis
}

When considering complications in colonoscopy, very few cases are found to be caused by preparation with drinking procedures $(1-4)$. We observed a perforation of an acutely inflamed diverticulum from drinking 5 litres of saline solution without any other mechanical manipulation. Barium deposit remaining in the diverticulum proved the direct link between the drinking procedure and the immediate perforation.

The male, 36-year-old patient presented with slight pain in the right side of the lower abdomen, that only occurred with deep palpation of this region, spreading to the center and opposite side. The laboratory findings showed leukocytosis of $13000 / \mu \mathrm{l}$ and a normal blood sedimentation; a first radiograph was normal apart from a "calcified plebolith" in the projection to the left ileosacral articulation (Fig- ure 1). After complete pain improvement and normalization of white blood count, colonoscopy preparation was undergone on the fourth day of hospitalization by drinking 51 of a saline solution. The patient was then found sitting on the toilet, sweating, with an acute, diffuse abdominal pain, displaying abdominal muscular defense, with absent intestinal noises. A second radiography revealed a few liquid-filled bowel loops that were interpreted as appropriate to the recently performed drinking procedure. Colonoscopy was then started, demonstrating a highly inflamed diverticulum in the sigmoid at $30 \mathrm{~cm} a b$ ano. After stopping colonoscopy immediately, a third radiograph showed multiple bowel loops, indicating a complete ileus. Body temperature rose to $38.6^{\circ} \mathrm{C}$, leukocytes and CRP were also elevated. 


\section{s82 Unusual Cases and Technical Notes}

During retrospective analysis of the third radiograph, a change in the shape of the "calcified phlebolith" was noticed, developing spikes and separating a second "drop" in the second radiograph taken immediately before colonoscopy (Figure 2). The patient now revealed that a barium-examination of the large bowel had been performed 1 year ago: Thus, the "phlebolith" could be identified as a persisting barium deposit in the diverticulum, permeating into the altered tissue, indicating and proving its perforation after the drinking procedure coinciding with maximum pain before colonoscopy.

\section{A. Gabel, S. Müller, K. Häntzsche} Karlsruhe, Germany

\section{Reference}

1. Frühmorgen P, Demling L. Complications of diagnostic and therapeutic colonoscopy in the Federal Republic of Germany: results of an inquiry. Endoscopy $1979 ; 11: 146-50$.

2. Heymann TD, Chopra K, Nunn E, et al. Bowel preparation at home: prospective study of adverse effects in elderly people. Br Med J 1996; 313: $727-8$.

3. Ottenjann R, Classen M. Gastroenterologische Endoskopie. Stuttgart: Enke, 1991: $331-82$.

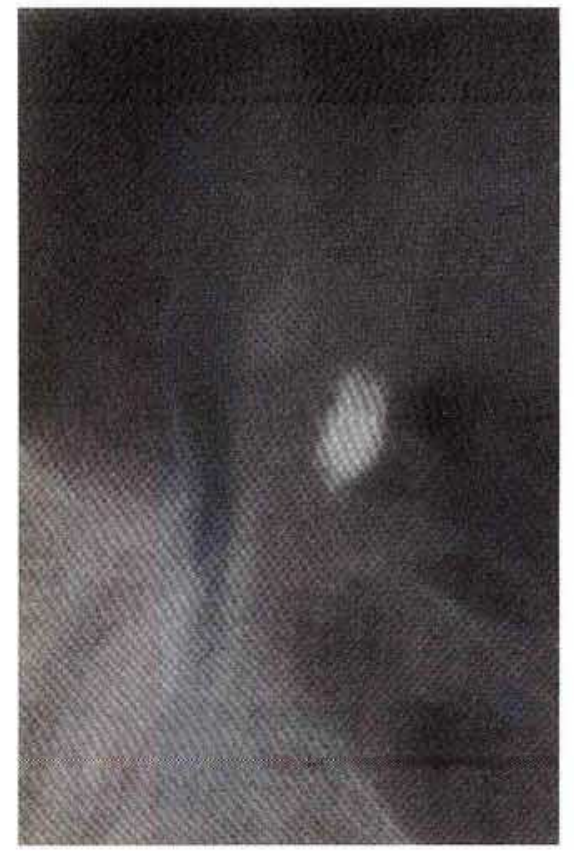

Figure 1: A smoothly contoured drop-like barium deposit shows the intact diverticulum prior to preparation for colonoscopy.

4. Rosenbusch G, Reeders J. Kolon. Klinische Radiologie und Endoskopie. Stuttgart: Thieme, 1993; 68: $32-4$.

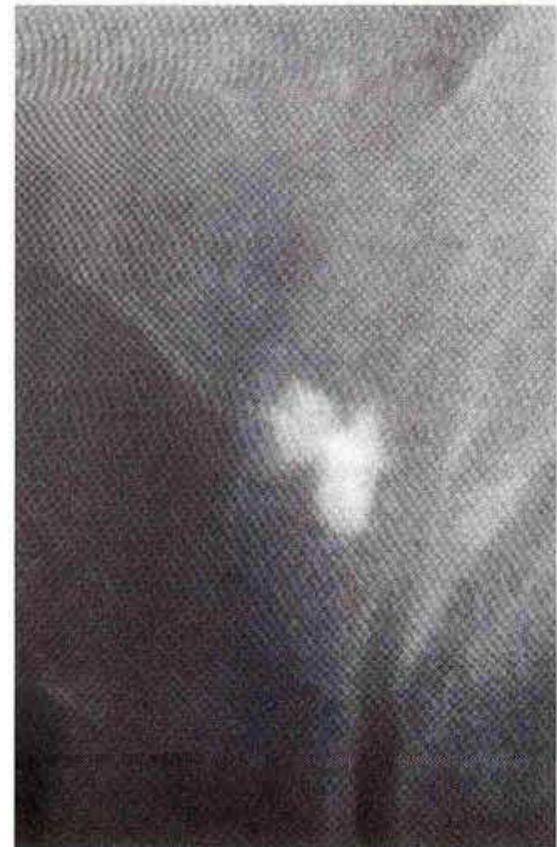

Figure 2: Immediately after the drinking proce dure and development of acute abdominal pain a change in the shape of the barium drop with permeation into the tissue in the form of spikes is seen.

Corresponding Author

A. Gabel, M.D.

Bahnhofstrasse 8

76137 Karlsruhe

Germany 